\title{
Visual Modeling of Chinese Temple Construction for Student Education
}

\section{Adrian Hadipriono Tan, The Ohio State University}

Adrian H. Tan is a graduate student at the Ohio State University. He has a B.S. in Computer Science and Engineering and an M.S. in Civil Engineering from the Ohio State University, and is currently working towards a Ph.D. in civil engineering and construction with a focus on computer graphics and virtual simulation for engineering education.

\section{Mr. Shilun Hao, The Ohio State University}

Shilun Hao is a graduate student at the Ohio State University. He has a B.S. in Civil Engineering from the Beijing University of Civil Engineering and Architecture, and is currently working towards an M.S. in Civil Engineering at the Ohio State University, with a focus on the digital reconstruction of ancient architecture.

\section{Mr. JIYUAN LI, The Ohio State University Civil Engineering Department}

Jiyuan $\mathrm{Li}$ is a graduate student at the Ohio State University. He has a B.S. in Civil Engineering at the Chang'An University, PR China. He is now currently working towards a M.S. in Civil Engineering and Construction with a focus on computer graphics and virtual simulation for engineering education.

Lei Zhao,

Lei Zhao is a graduate student in Ohio State University. He obtained a B.S. in Civil Engineering in China University of Geoscience, and is now doing his M.S. in Civil Engineering and Construction and concentrating on research and modeling for foundations of ancient architecture.

\section{Prof. Fabian Hadipriono Tan, The Ohio State University}

Fabian Hadipriono Tan has worked in the areas of construction of infrastructures and buildings, failure assessment of buildings and bridges, construction accident investigations, forensic engineering, ancient buildings, ancient bridges, and the ancient history of science and engineering for over 40 years. The tools he uses include fault tree analysis, fuzzy logic, artificial intelligence, and virtual reality. 


\title{
Visual Modeling of Chinese Temple Construction for Student Education
}

\author{
Adrian H. Tan, Shilun Hao, Jiyuan Li, Lei Zhao, and Fabian H. Tan \\ Department of Civil Engineering \\ The Ohio State University
}

\begin{abstract}
In Chinese culture, temples hold a high degree of importance. The intent of this paper is to introduce a construction program that can be used to educate students in the complete erection sequence of these temples, which has not been discussed before in the literature related to their construction. A typical Chinese temple consists of its foundation, elevated floor platform, walls and columns, and roof system. An intelligent system that includes graphical simulation is presented as a learning tool for our students. Currently, the discussion of the system in this paper is limited to a distinctive part of Chinese roof temples known as the dougong.
\end{abstract}

\section{Introduction}

The Chinese temple (Latin: templum), commonly called a si or a place of worship, is a relatively simple rectangular building with an often complicated roof structure. It often consists of a single large room furnished with lavish religious ornaments, and is generally constructed on an elevated platform which worshippers will need to go through steps to reach. Chinese temples are among the most iconic structures in architecture, and have long been treasured as symbols of China's history, art, religion, and culture. These temples often constructed from various different parts interlaced together, and integrated into their environment in such a way that they are emphasized among the surrounding landscape. Because the architecture of China is vastly different from that of other cultures, it is often difficult to broach the subject of Chinese construction to student audience. The vast quantity of components that made up these temples means that the construction procedure is not straightforward for our students to learn. To overcome this problem, graphical simulations that recreate the construction procedures of Chinese temples are introduced as learning tools for our students. As presented in this paper, objects developed in a 3-D environment, beginning with the erection of foundations and floors, walls and columns, and the roofing components that give Chinese temples their distinctive feature, are easier to visualize than textual descriptions and blueprints.

As a symbol of Chinese traditional culture, the dougong has been investigated by architects and scholars since its inception. The categories of studies on dougong include mechanical properties, anti-seismic performance, the preservation of dougong in ancient buildings, the graphical simulation of dougong, and the use of dougong as a decorative element in modern 
buildings. The majority of the studies on this topic are written in Chinese, which hampers the interest of foreign scholars; the difficulty of understanding ancient Chinese terms may also prevent Chinese people from fully appreciating dougong. However, a systematic and graphic simulation of the construction process of dougong in 3D graphics, encompassing the types of dougong recorded in the famous architectural scriptures, the Yingzao Fashi $i^{4}$ and the the Gongcheng Zuofa ${ }^{6}$, has not been developed until now. In ancient China, building specifications were transferred between generations of architects due to the lack of technologies available. In the Yingzao Fashi, descriptions of the construction process are primarily recounted as textual statements with sparse, incomplete, inaccurate and disproportionate illustrations.

Following the emergence of the Yingzao Fashi and the Gongcheng Zuofa, another masterpiece, Dougong, was written and published by Dehua $\operatorname{Pan}^{7}$, who explained the construction operations of all types of dougong, as recorded in the previous sources. Compared with the Yingzao Fashi, it is an extraordinary advancement because the descriptions in Dougong are more readable and understandable; the most significant aspect is that the author provides engineering drawings of all components of all types of dougong, which serve as a basis for part of the $3 \mathrm{D}$ graphical simulation presented in this paper.

All of these sources focused on only one particular component of the Chinese temple; other aspects such as the foundation and roofing were not considered in depth. This paper not only allows the knowledge of these sources to become disseminated to a learning audience, but also broadens their established scope, by presenting a construction process for an entire temple from start to finish.

\section{Foundations and Floors}

As with many other structures, the first component of a temple is its foundation. A temple is as good as its foundation, which in turn depends on the soil supporting it. To an engineer, the term 'soil' applies to any underground mineral and some organic materials including rocks, cobbles, gravels, dirt, sand, clay, silt, and mud. An ideal situation is for a structure to be placed directly on a competent soil or strong soil such as a hard pan, bed rock, cemented gravels, or very dense clay that, unlike an incompetent soil, does not settle and will not cause any damage to the temple or the superstructure. Ancient temple builders most likely understood that building a si over hard soil would considerably reduce the risk of the temple being damaged. Thus, they 
would first survey and find a layer of bedrock upon which the si could be built. These ancient builders would then construct the base of their temple directly upon the hard soil, which became the foundation for the columns and walls. In this case, soil excavation would be minimized, and workers would simply level the ground. But what if the competent soil is located deeper in the ground and the temple wall is much heavier? Several of the major Chinese temples researched for this paper rest on hard soil; however, several others were built on regular soils where the competent soil was located deeper below ground. Without adequately strong foundation, these temples would not last long. A typical foundation and floor bases that support Chinese temples are presented in 3-D graphical construction sequences for the foundation and floor base of the Hall of Supreme Harmony (ca. 64-m by 37-m) in the Forbidden City in Beijing, China (Figs. 1 and 2) and for the floor base of the Hall of Central Harmony (ca. 24-m by 24-m) also in the Forbidden City (Figs. 3 and 4). Both were first built during the Ming Dynasty (1368-1644) and were rebuilt and renovated during the Qing Dynasty (1644-1912). Given these illustrated 3-D sequences, students are expected to obtain a clear picture of the foundation that supports the walls, floor, and columns of Chinese temples. The Hall of Supreme Harmony, whose front view is shown in Fig. 1, has a rectangular shape. The building has a raised floor platform; Fig. 2 shows the construction sequence of the foundation and floor base. The top view of the finished floor base is shown in Fig. 3. Its foundation consists of numerous piles driven to the ground, on top of which soil was placed and compacted in layers. Then stone blocks were placed to form the perimeter of the rectangular floor pattern; steps were also installed to reach the raised floor platform. Inside this perimeter, more stone blocks were installed as the bases for columns, and stone plinths were then placed on top of these column bases. Between these column bases masonry strip foundations, functioning as grade beams, were installed. These strip foundations divided the floor space into cells that were filled with soil up to the floor elevation level. Finally, installation of stone slabs would complete the temple floor. Notice that in Stage VI of Fig. 2, the column plinths project from the floor; the circular columns supporting the structure would be placed on these plinths.

The Hall of Central Harmony is depicted in Fig. 4; its frontal view is depicted on top of the figure, while the detail of the elevated floor is shown at the bottom. Similar to the Hall of Supreme Harmony, this smaller square-shaped temple was also constructed on an elevated floor platform that was constructed from marble. Fig. 5 displays the construction process of the 
elevated floor platform. Similar to before, the construction of this floor base began with the installation of the stone perimeter, followed by the placement of column bases and plinths inside the perimeter and steps outside the perimeter, all were from stone. Once these stone blocks were in place, masonry strip foundations (grade beams) were installed and soil was backfilled and compacted around them. Marble slabs were then placed on top of this compacted earth to function as the temple floor. The top view of the finished floor is shown in Fig. 6.

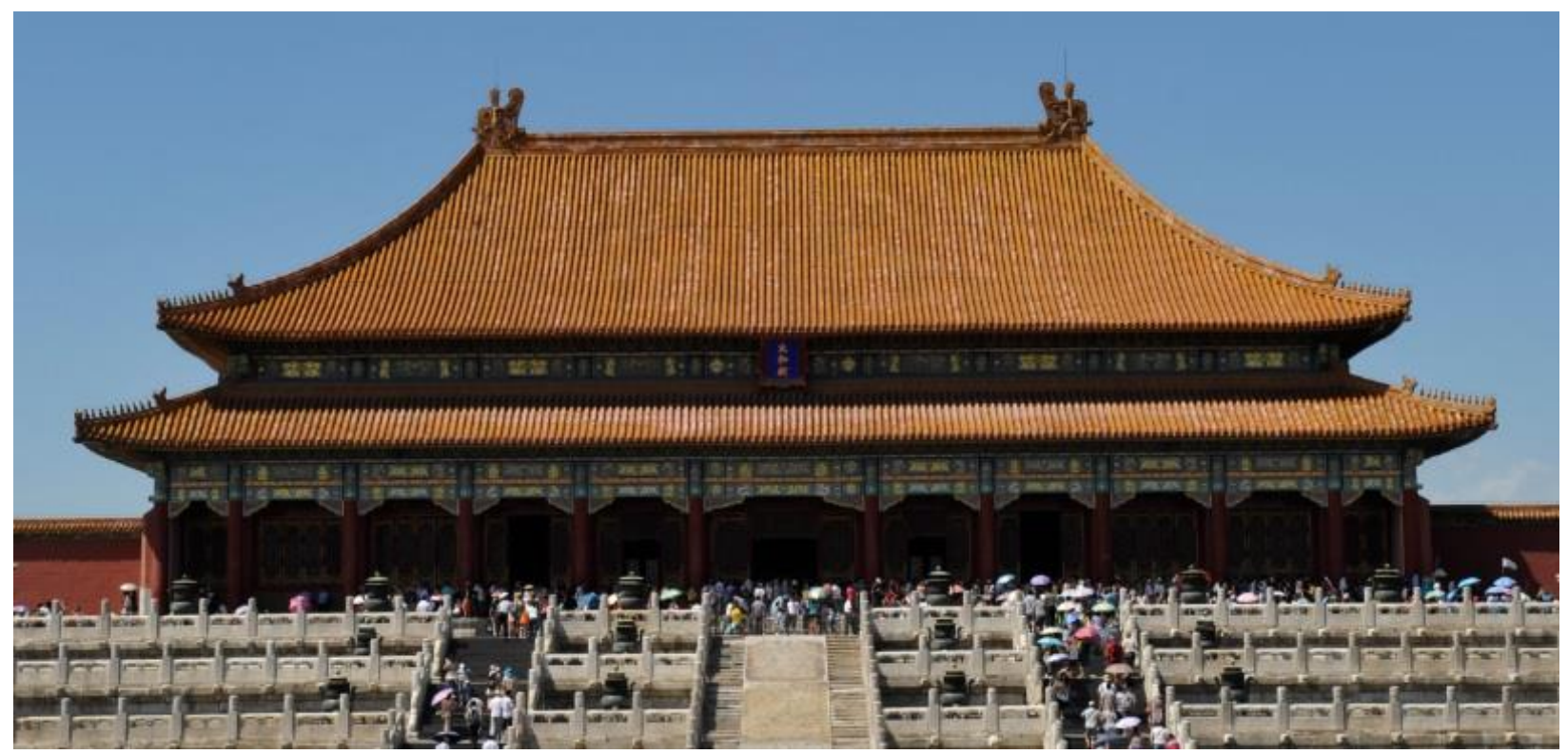

Fig. 1. The front view of the Hall of Supreme Harmony, Forbidden City in Beijing, China 


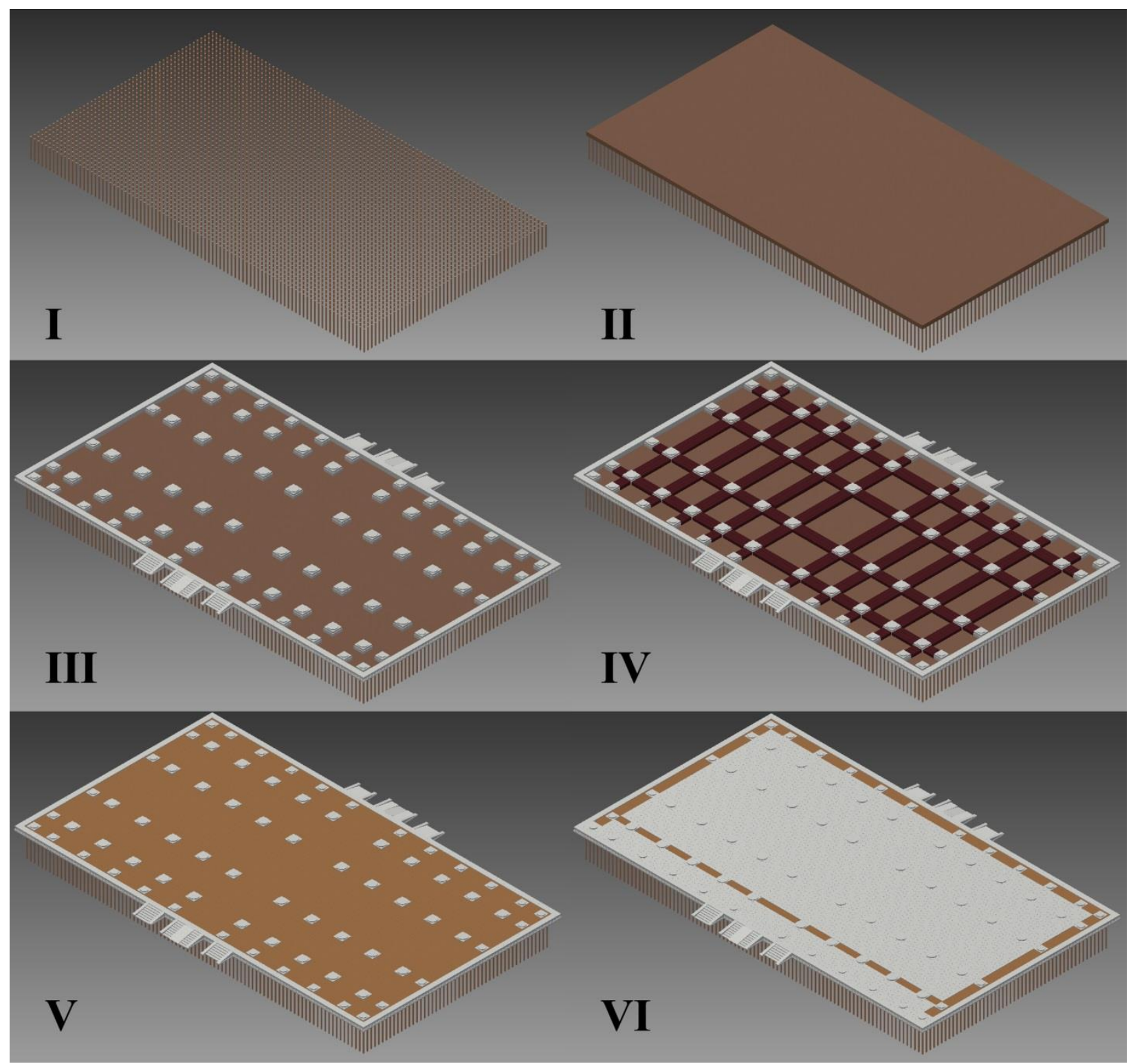

Fig. 2. Pile foundation and floor of the Hall of Supreme Harmony (ca. 64-m by 37-m) in the Forbidden City in Beijing: (I) Drive timber piles into the ground; (II) Place and compact soil on top of them to rise to desired elevation; (III) Install stone perimeter, place stone blocks inside the perimeter and compact earth around them; also install stone steps outside the perimeter; (IV) Place strip masonry foundations (grade beams) between column bases; (V) Place and compact soil in layers up to floor elevation level; (VI) Place floor slab. 


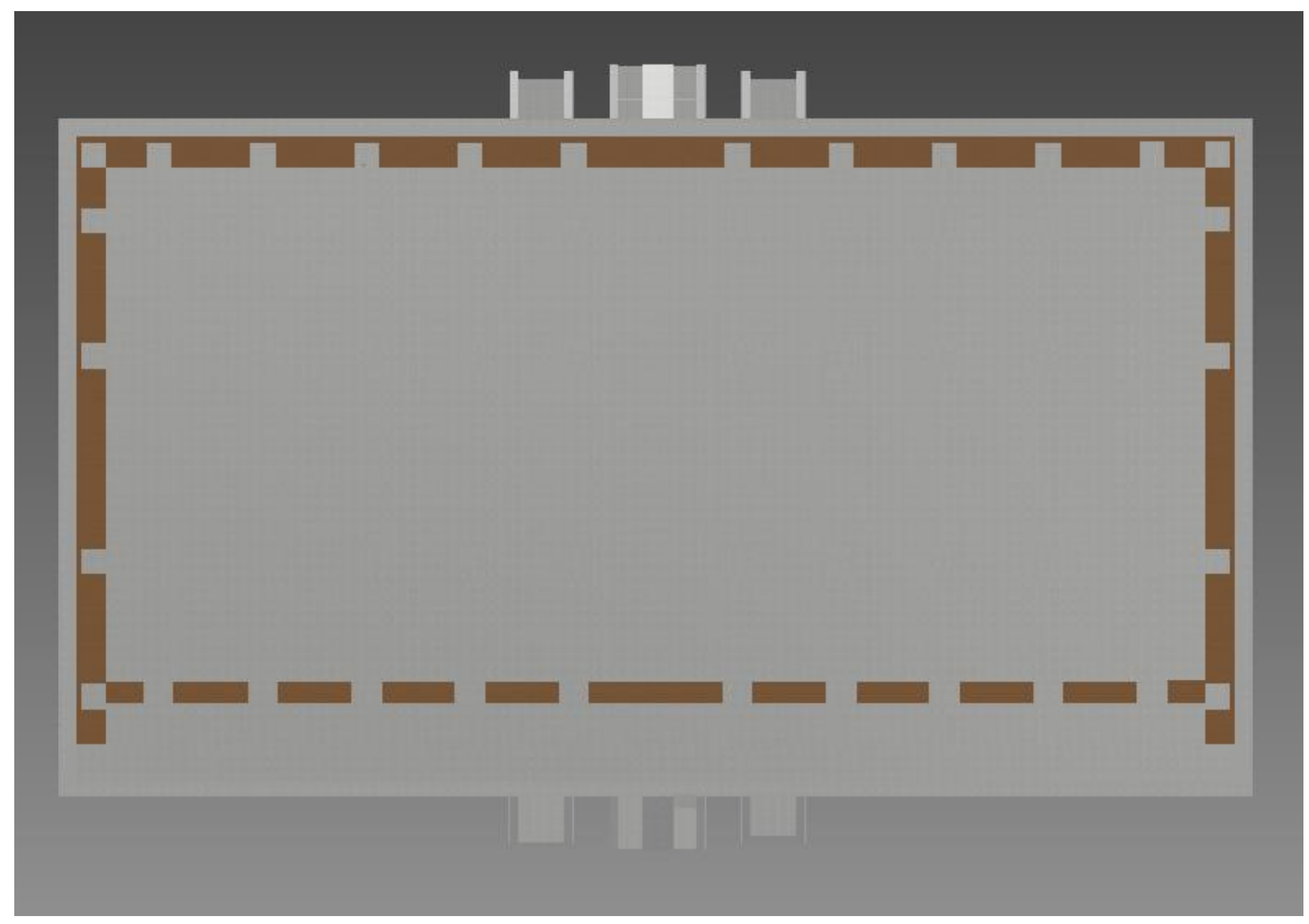

Fig. 3. Top view of the floor for the Hall of Supreme Harmony (ca. 64-m by 37-m) 


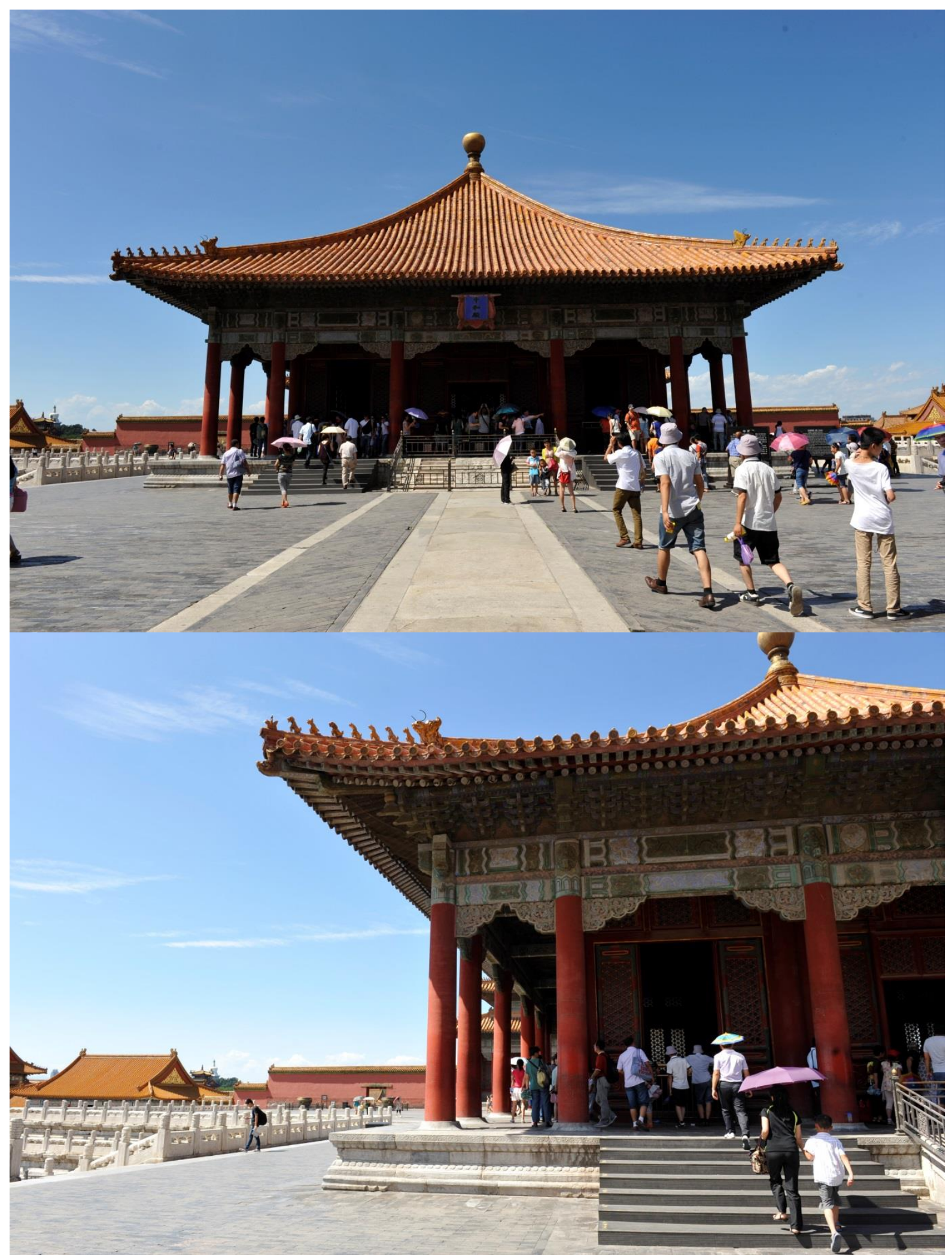

Fig. 4. The front view of the Hall of Central Harmony in the Forbidden City in Beijing, China (top) with its raised floor platform (bottom) 


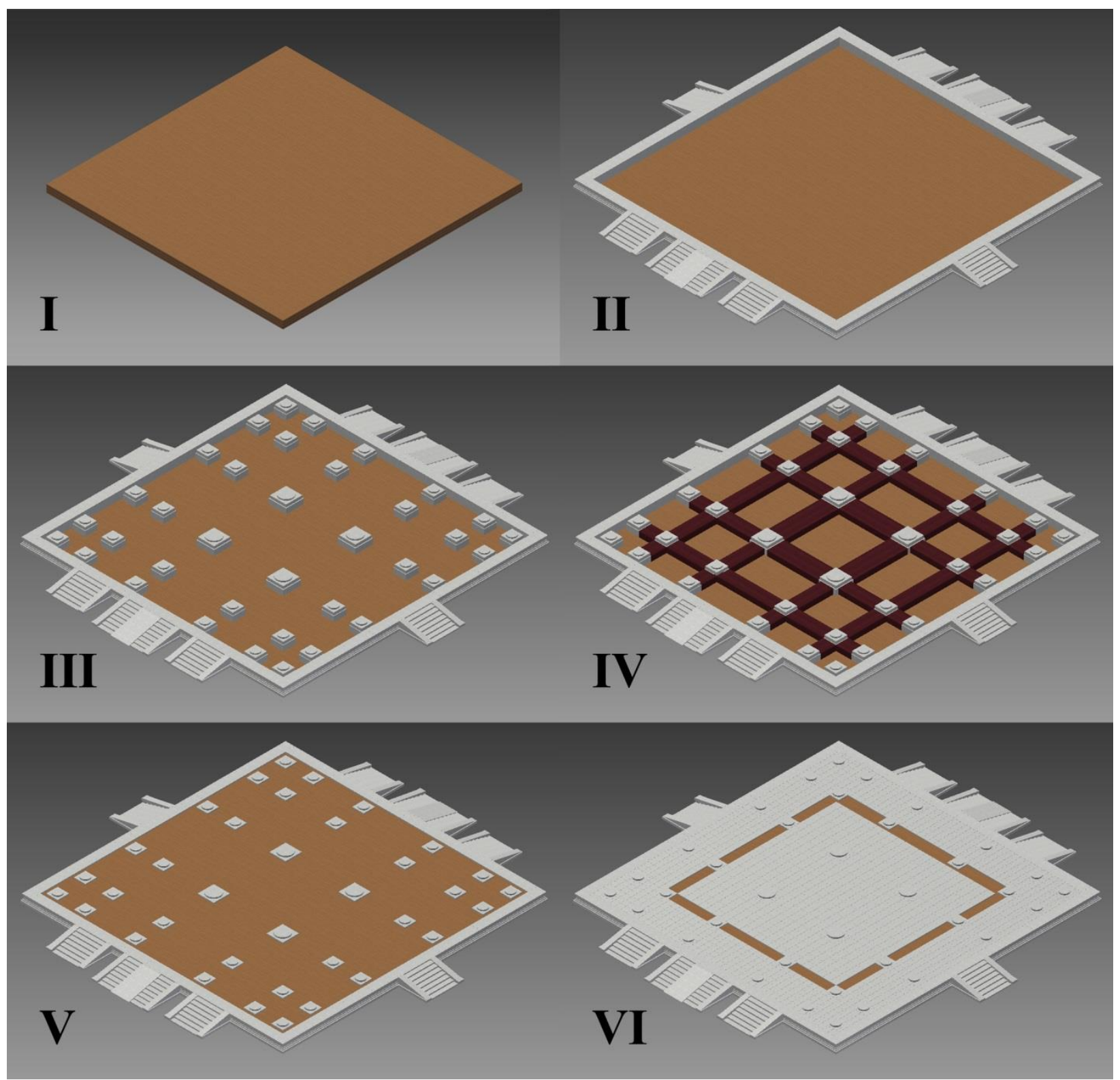

Fig. 5. The construction sequence of the raised floor platform of the Hall of Central Harmony (ca. 24-m by 24-m): (I) Compact earth for floor base; (II) Erect floor-base perimeter and stairs/steps from stone blocks: (III) Install column-base blocks inside this perimeter; (IV) Place strip masonry foundations (grade beams) between column bases; (V) Place and compact soil in layers up to floor elevation level; and (VI) Place marble floor slabs. 


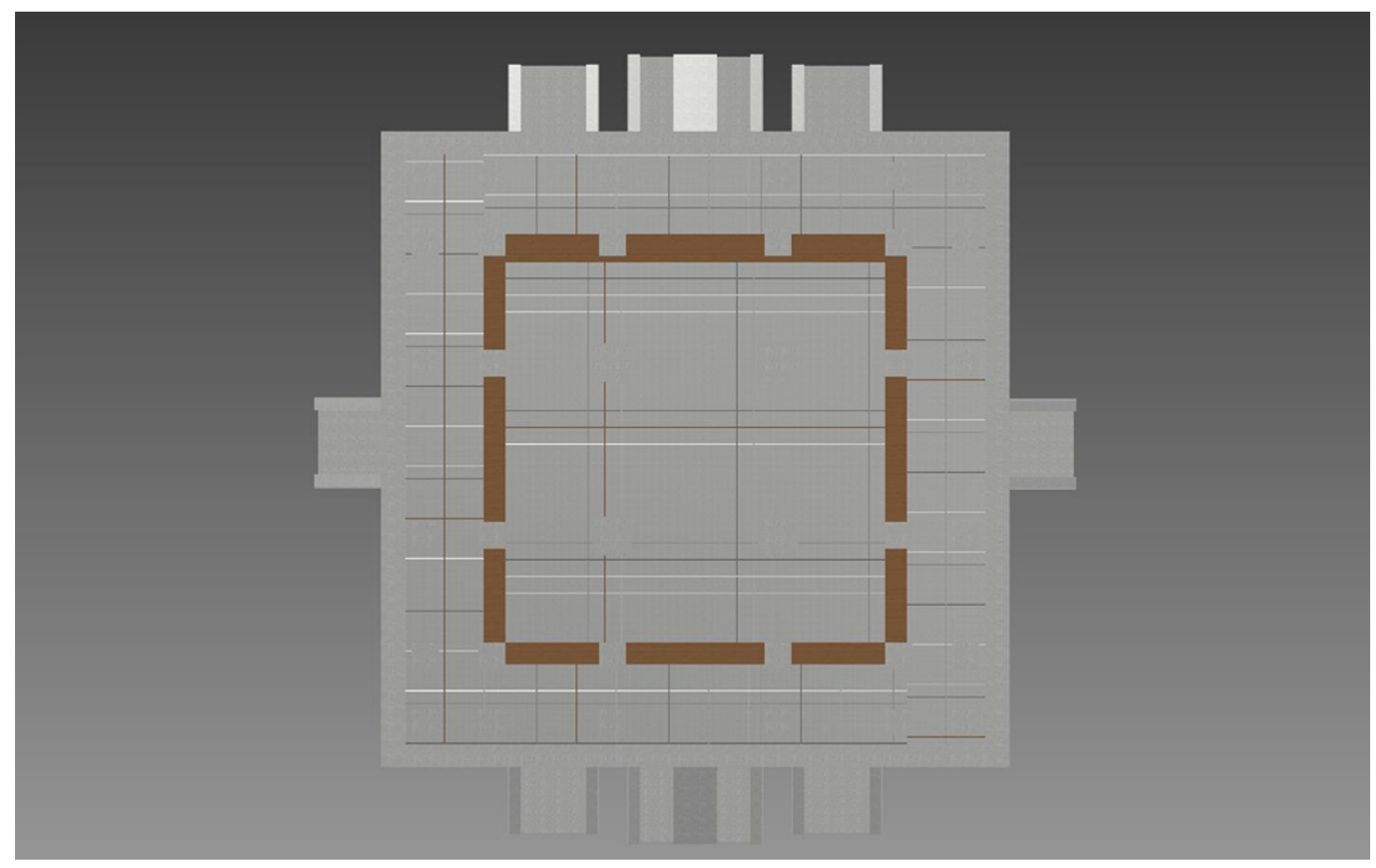

Fig. 6. Top view of temple floor plan of the Hall of Central Harmony (ca. 24-m by 24-m)

\section{Walls and Columns}

Walls and columns are central to the establishment of a Chinese temple. Despite the numerous variations of the construction materials, in general, temple walls were made of stone masonry, brick masonry, or wood; sometimes, a temple wall could be comprised of a combination of wood and masonry. After the completion of the elevated floor platform, plinths (slabs and bases of columns) were placed on top of it. Some of these plinths were made modestly but several were carved or crafted elaborately. Columns made from stones, masonry, or wood were then placed on these plinths (see Fig. 7). 


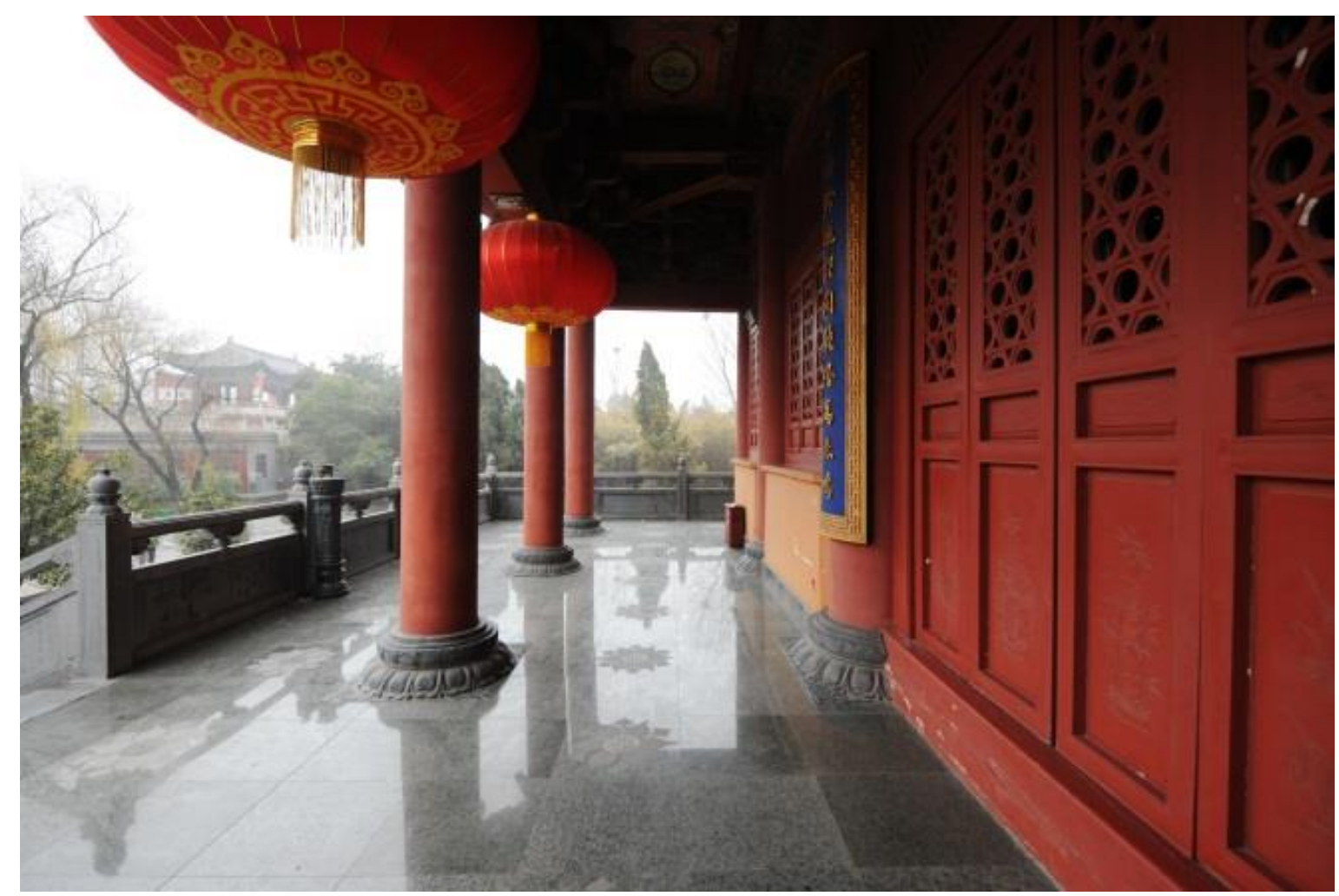

Fig. 7. The porch of Luoyang Temple depicting columns on the left that were installed independently, placed on carved stone plinths, while those on the right that were integrated with wooden walls. Columns and walls were resting on an elevated floor platform such as those illustrated in the previous figures.

Though walls and columns are integral components of buildings, buildings in ancient China were identified based on their roofs. The buildings commonly constructed by officials in ancient times were classified according to the shape of the roof $^{9}$; the types of single-roofed buildings were the wudian (hip roof), xieshan (gable and hip roof), xuanshang (overhanging gable roof), yingshan (flush gable roof), and cuanjian (pyramid roof). The ranks of single-roofed buildings, from least to most noble, were a combined category of the cuanjian, yingshan, and xuanshang, followed by the xieshan, and the wudian. The xieshan and wudian categories also have a double-tiered variant known as the chongyan (double-eaved roof), with the chongyan wudian (a combination of chongyan and wudian) being the nobler of the two types of double-roof. The Hall of Supreme Harmony is an example of a chongyan wudian roof, and was therefore ranked as the noblest in both roofing categories. The yingshan roof appeared in the Ming and Qing dynasties, while the other roof types date back to the Song dynasty. 
The wudian, which was a subject of a previous 3-D simulation study ${ }^{5}$, refers to a building with a hipped roof (all sides sloped downwards), with an absence of a gable. Fig. 8 shows the plan of a wudian with a single-tiered roof, while Fig. 9 depicts the 3-D model.

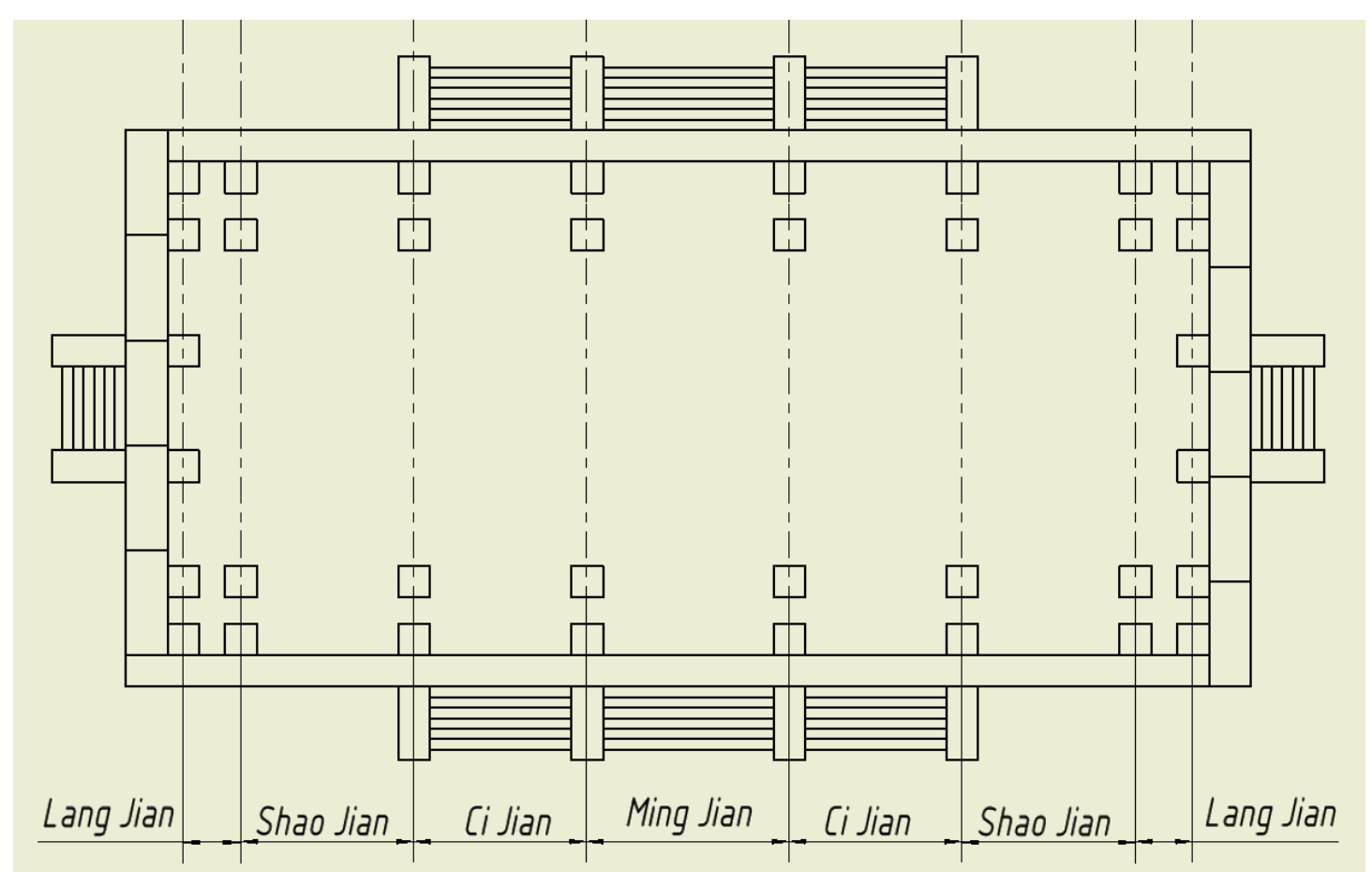

Fig. 8. A typical plan view of a wudian, depicting its walls and columns

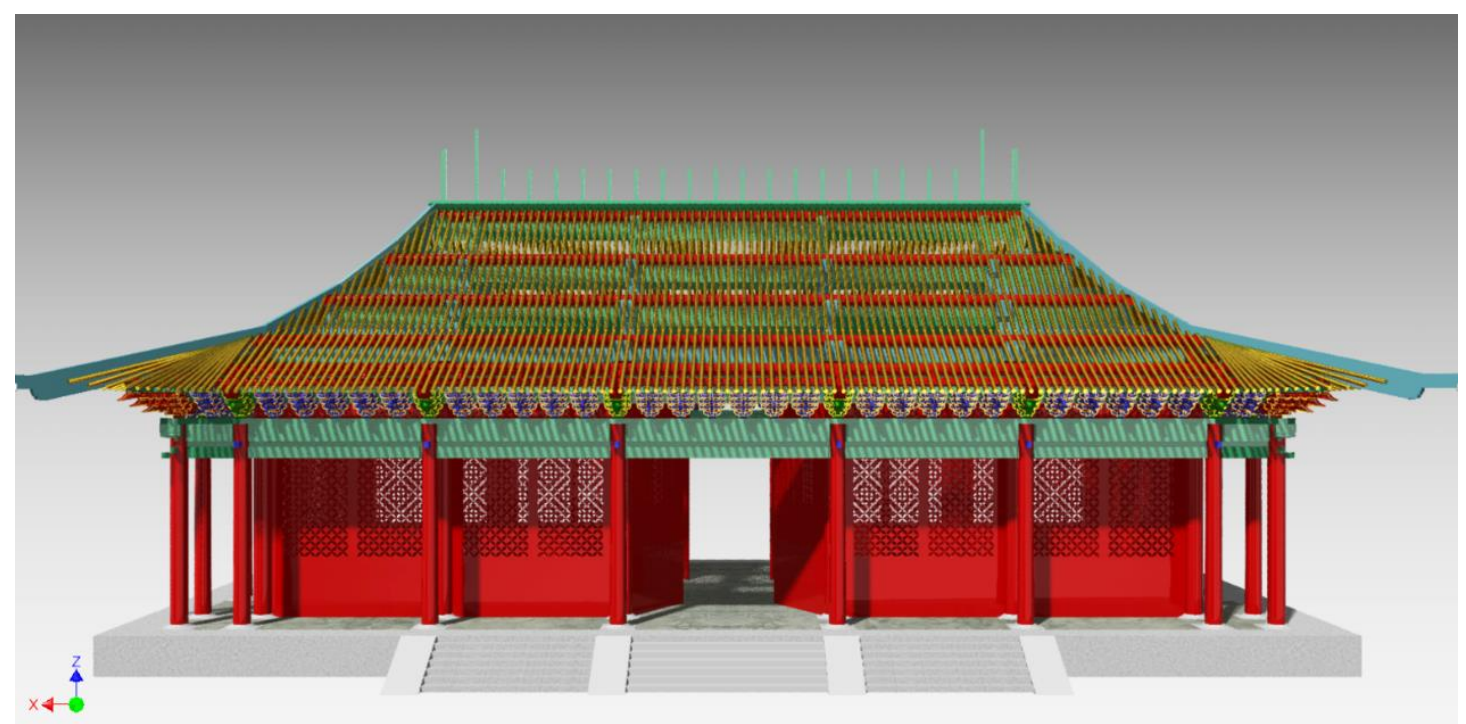

Fig. 9. A 3-D graphical model of wudian with walls and columns (internal and external) 


\section{The Roof}

As construction continued up to the roof level, the features and components became more complicated. One contributing factor to this complexity is the fact that these components were made from timber, which allowed the builders to craft and engineer their connections to a level that could not be found elsewhere, except in Japan and Korea (owing to the similar roots of their construction traits). Unlike the roofing system we often encounter in modern roof buildings where trusses are regularly employed, the roof support system in Chinese temples differs greatly in the sense that it consists mainly of horizontal girders that support vertical posts as shown in Fig. 10. The brackets supporting the horizontal components are called dougong. Fig. 11 displays a sectional view of a wudian with numerous dougong.

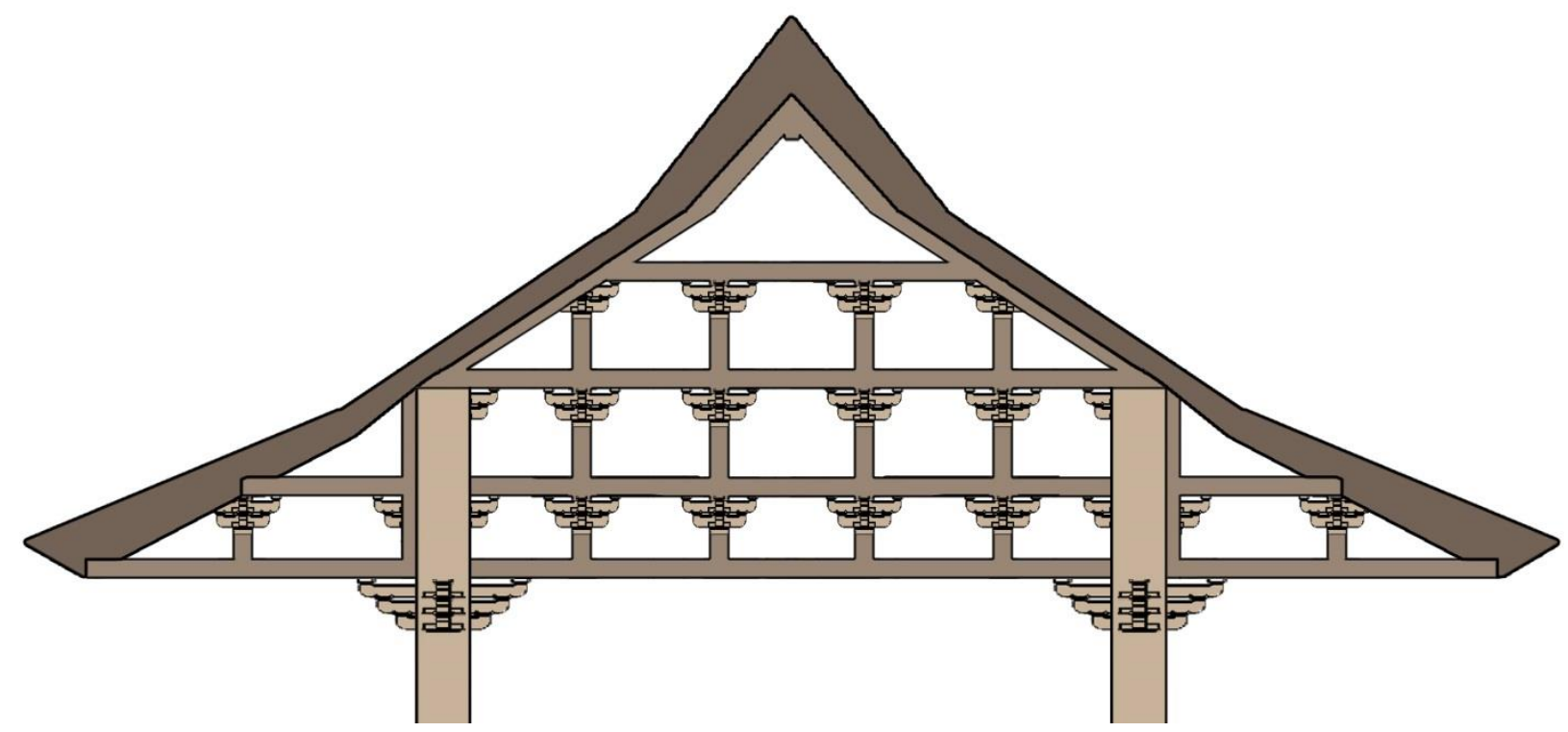

Fig. 10. A sketch of a typical Chinese temple roof support system, consisting of girders and short posts. Layers of brackets attached to columns and posts, supporting the girders, are called dougong. 


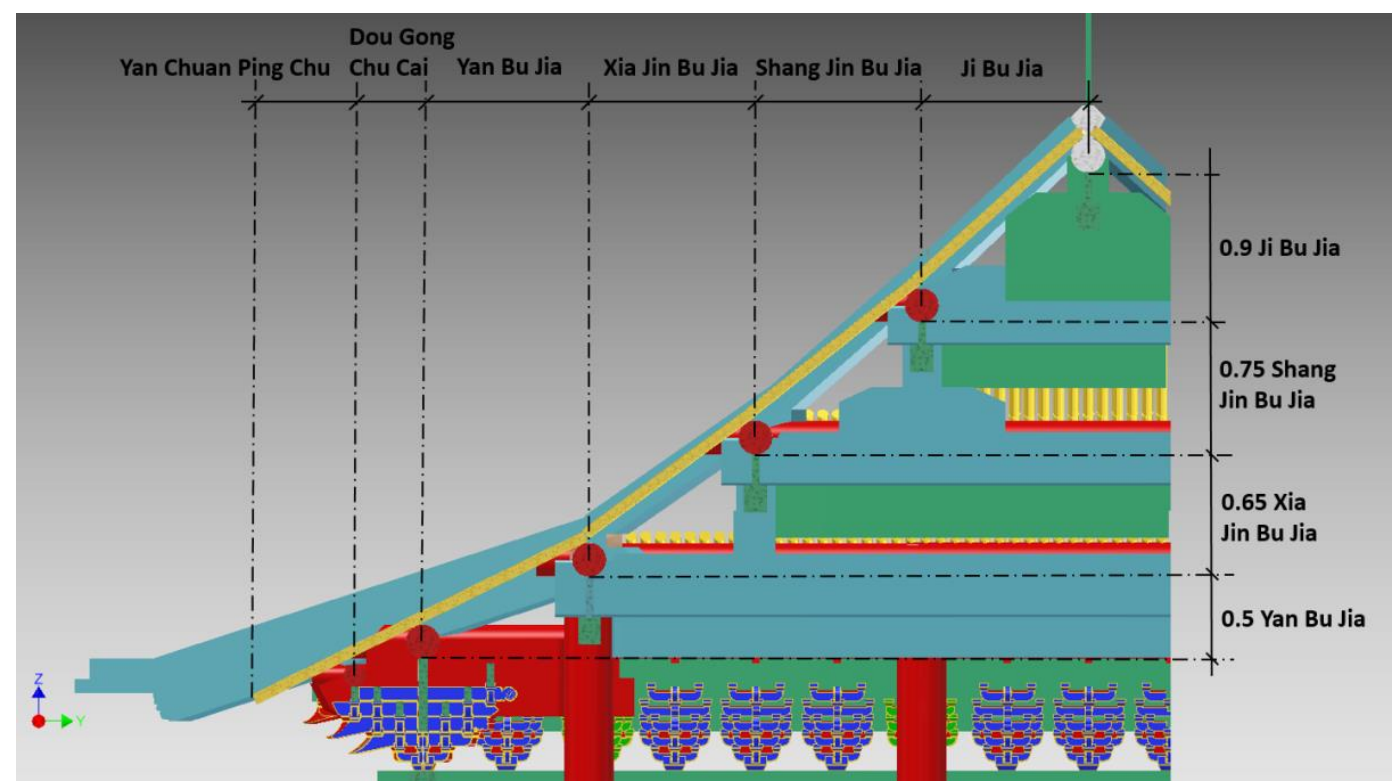

Fig. 11. A half section of a wudian roof with a series of dougong, or brackets (in blue at the bottom) constructed to support the eaves.

The roof erection began with the installation of Pingban Fang, or perimeter girders, on top of the external columns/posts as shown in Fig. 12. The intricate connections of these girders and columns are animated so that students can visualize, review, and familiarize with the intricate installation sequence. Fig. 13 displays a screen shot of the connection details. The erection process continues with other components until roof installation is completed. With these models, students repeat the animation of the roof erection process until they are familiar with the concept of erecting the temple roof. However, the most intricate parts are yet to come.

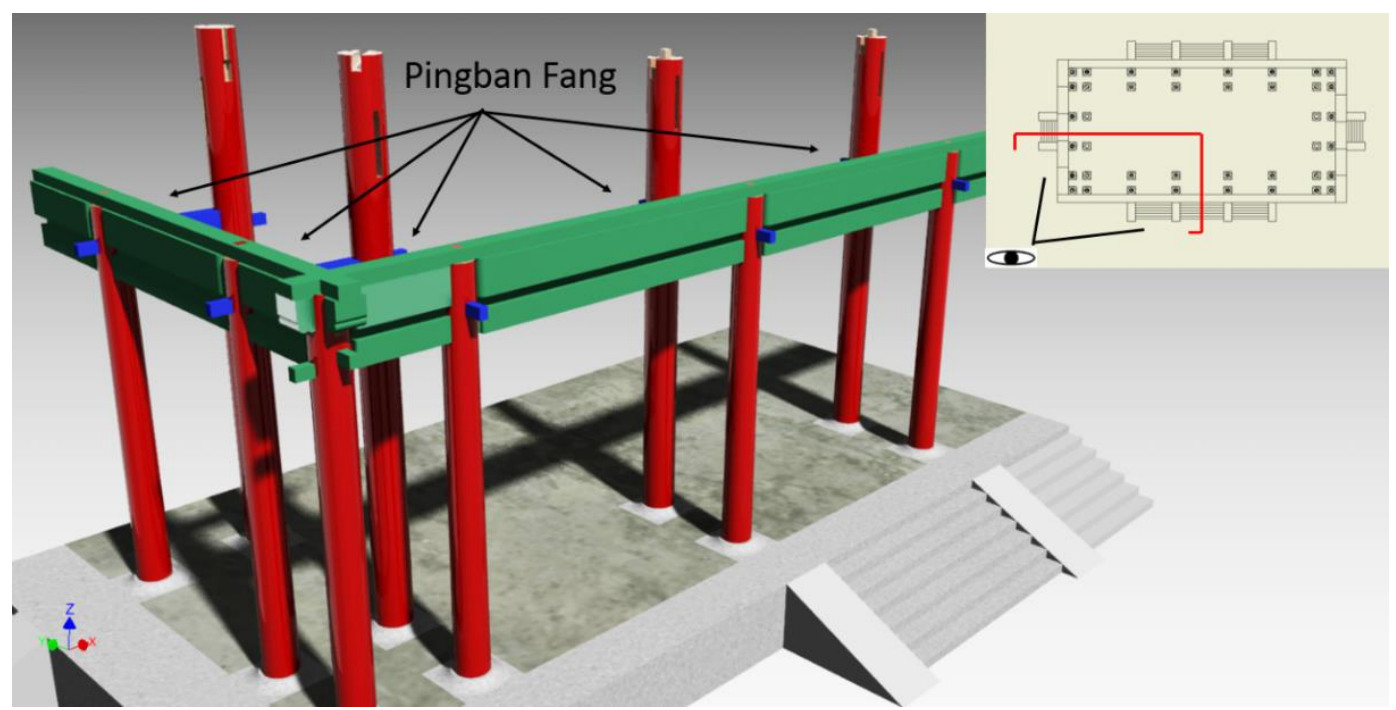

Fig. 12. Installation of Pingban Fang or perimeter girders on top of the posts. 


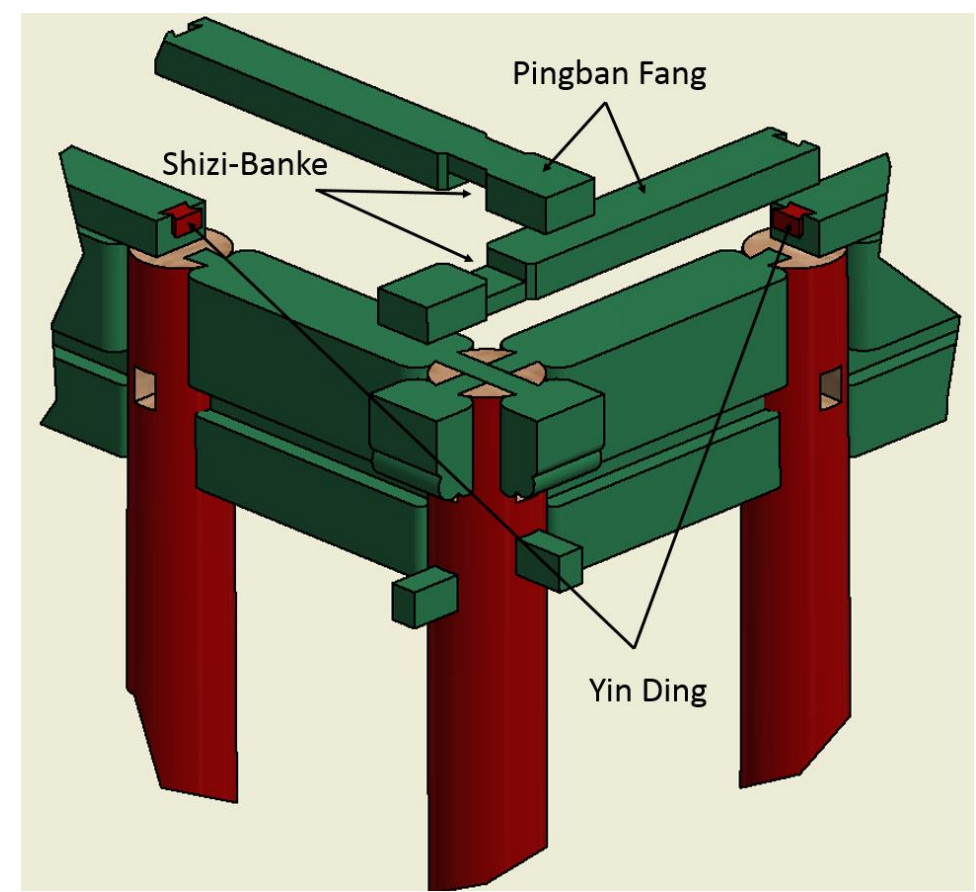

Fig. 13. Connection details between perimeter girders and columns; it would have been challenging for students to comprehend how to build and assemble these intricate components without 3-D animation models.

\section{Dougong}

A unique trait of Chinese architecture and construction engineering of its roofing system, the dougong can be translated into 'cap and block' bracket system. A dou is an inverted cap holding a gong, a block, or a beam on top of it, and each dou has a small hole drilled in the bottom into which a matching pin protruding from a gong is mated. Skillfully made dougong joinery does not need fasteners such as nails and glue. The earliest known dougong systems are found in ceramic models of funerary buildings, especially those from the Eastern Han Dynasty, ca. AD $20-220$ (Fig. 14 left). The dougong system has since become such an important feature that it continues to be featured in modern, newly reconstructed temples throughout most of East Asia (Fig. 14 right). The earliest written documents of dougong system were found in the Chinese building standards called the Yingzao Fashi, which was first compiled and introduced in AD 1103 in the Song Dynasty ${ }^{1}$, and in the Chinese construction manuals and specifications known as the Gongcheng Zuofa in AD 1734, compiled and enforced during the Qing Dynasty ${ }^{8}$. 

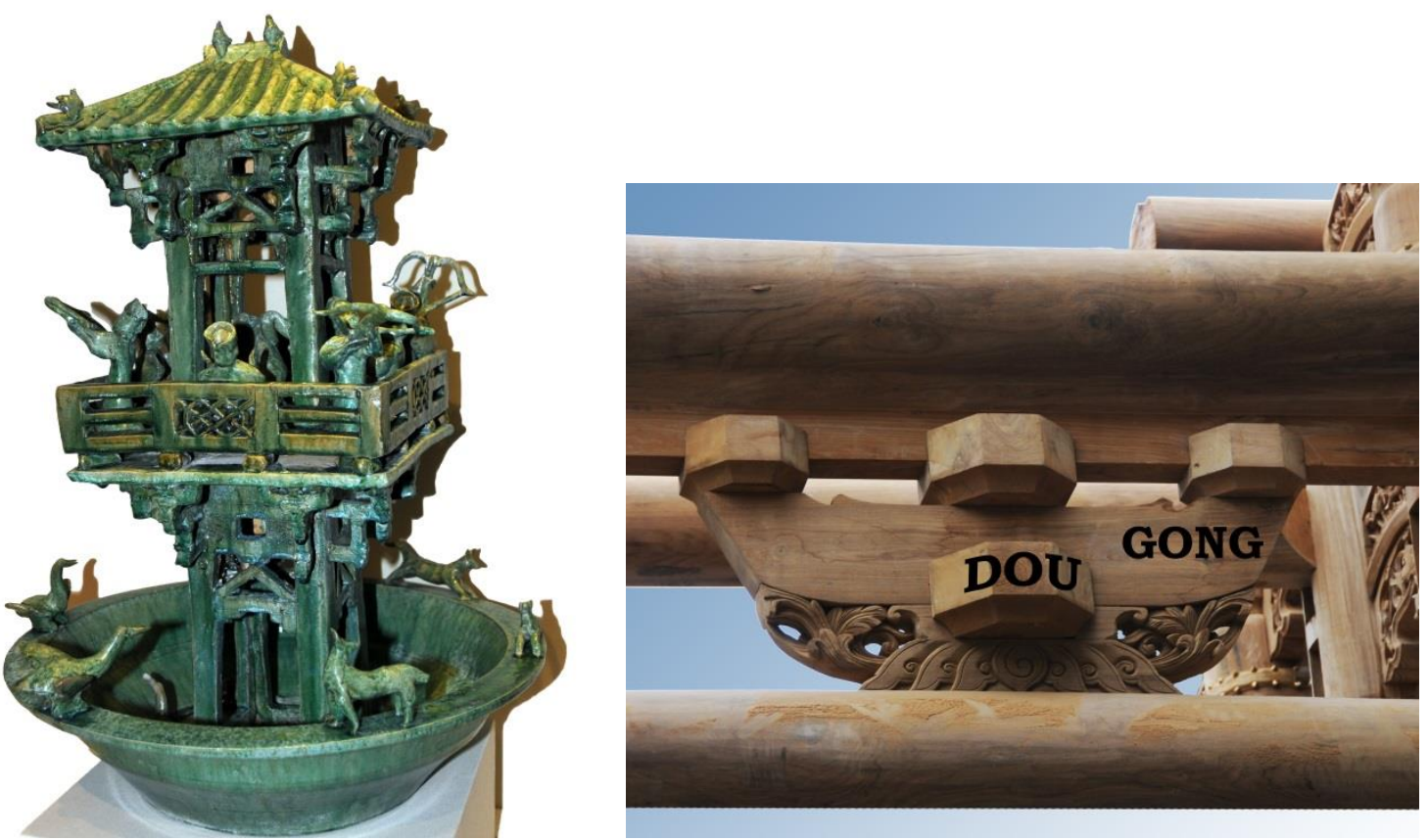

Fig. 14. A glazed funerary ceramic model of a pavilion from Eastern Han Dynasty, AD 25 220, showing an early design of dougong (left, Cleveland Museum of Art) and a modern dougong (right, a reconstructed temple in Shanghai).

The design and engineering of dougong technology evolved with time. Each China's dynasty has its own design style. Each style is often characterized by numerous types of dougong with numerous levels. For example, a recent study of dougong conducted by one of the authors, focusing on the Song Dynasty (AD 960 - 1279), alone involves 160 different types of dougong systems. This could by daunting for students to understand the construction concept without the aid of static and dynamic step-by-step graphical assembly processes.

One example of a static assembly process is shown in Fig. 15 for the 7-level Shang Ang Puzuo (a type of Song Dynasty dougong). The assembly process shown in this figure becomes a part of a dynamic digital graphic model embedded into the Intelligent Dougong System discussed in Section VII. 


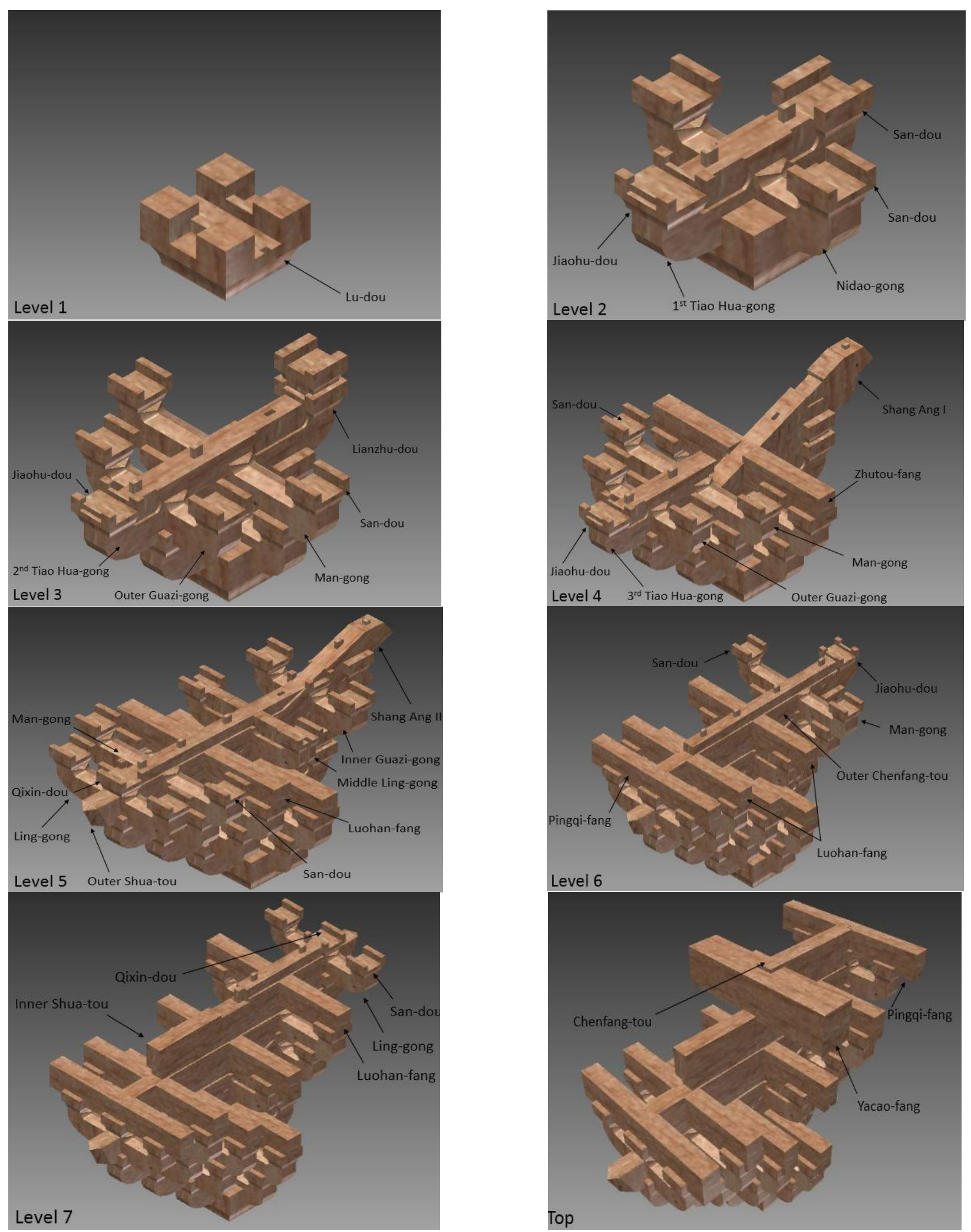

Fig. 15. Stages in level-by-level assembly of a 7-level Shang Ang Puzuo (a type of dougong)

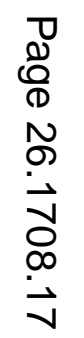




\section{Digital Models}

Digital technology, especially computer graphics, has been important in both the study of ancient architecture and the demonstration of it in education. Physical models, while practical for aiding in the understanding of this particular topic, can only go so far, in the sense that students can only see the outside of the monument once it is complete, and may not be able to view specific details that are concealed by the exterior. For a method of construction that relies heavily on the internal connections between its components, this may not seem like much of a problem with a physical model because the act of assembling it will often suffice. However, for a modular system as large and complex as a complete temple - for even the smaller "Joss houses" built in some old Western mining towns could top out at over twelve by sixty feet in area and two stories tall $^{3}-$ a down-scaled physical reconstruction may be too tedious for a classroom demonstration.

A more efficient alternative, and one that may likely see increasing use in the educational field, is a computer-generated model that can be assembled in a virtual environment. This means that the components of the model can be created as separate objects and, for a modular assembly with large numbers of repeated components, specific sections that require large numbers of parts can be pieced together at a much faster pace. A digital assembly also allows for the construction of components that would not normally be considered in a physical model due to specific circumstances: the foundation, for instance, requires understanding of how the ground would have been excavated and prepared for the placement of the building, which a digital model would be able to demonstrate efficiently. Full-scale digital models can also be viewed through a virtual camera traveling through the environment, and the ability of a digital model to be disassembled and reassembled without long-term physical damage to the structure may also enable students to analyze interior components that would not normally be visible otherwise. 


\section{Implementation}

Although the modeling of the dougong processes is useful for cataloguing purposes, disseminating knowledge to the public is also important. This is the reason for the creation of an intelligent temple-creation system. The system presented is an extended version of the Intelligent Dougong System (IDS) created by Hao et al. ${ }^{2}$ which, as described previously, simulates the construction process of Song-style Dougong specifically and also enables students to select the sets of criteria for different types of Dougong (Fig. 16). After the WELCOME page (Fig. 16-IL) students can go to the INTRODUCTION page to view the background information, the terms and other related information in textual and graphical form of the dougong (Fig. 16-I-R). In the COMPONENTS stage (Fig. 16-II-L) students can check the major components in Song-style dougong using several methods, including introductive descriptions, 3-D models with various angles, and multi-view engineering drawings. Next, students can go to the SELECTION stage (Fig. 16-II-R) to choose options in each category to determine the appropriate dougong. Here students can go to the knowledge base that contains more than 144 different types of Song-style dougong. In this page students can filter the expected dougong from the decision tree. Then, by pressing the NEXT button (Fig. 16-II-R), students will be furnished with information about the 3-D models, multi-view engineering drawings, and exploded views for each level for the 20 different types of Song-Style dougong The dimensions of a selected dougong is presented when they select the DIMENSION page (Fig. 16-III-L). If the ZOOMED PICTURE page is selected (Fig. 16-III-R), a 3-D model of the selected dougong is prompted. The associated photo is presented when PHOTOGRAPH page is pressed (Fig. 16-IV-L). Students can then view the corresponding animation of the installation of the dougong when the ANIMATION page is selected (Fig. 16-IV-R). 

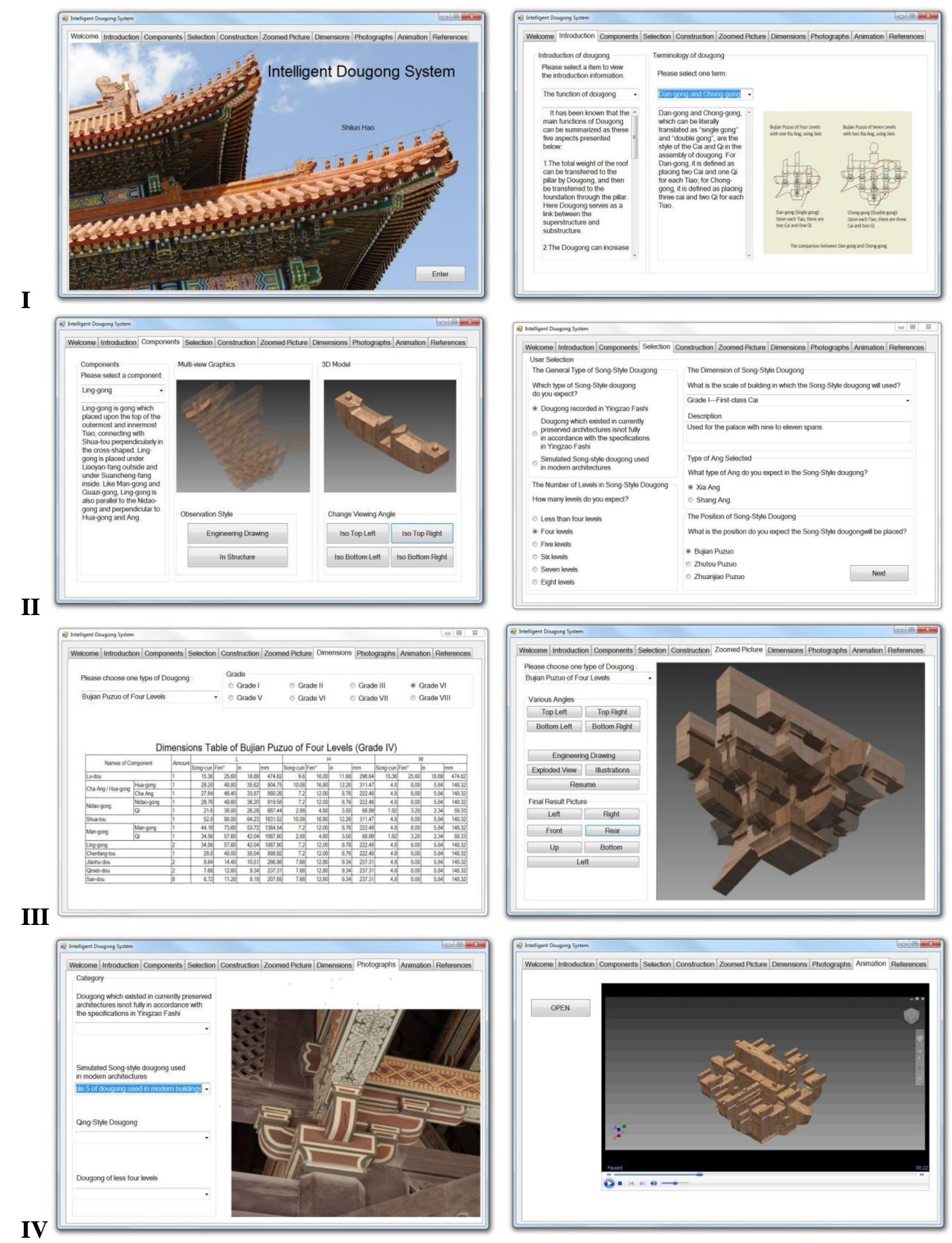

Fig. 16. The interface of the Intelligent Dougong System (IDS). 


\section{Discussion}

Although the simulation discussed above specifically focuses on dougong and temple construction specifically, the educational principles that it employs can be applied to other similar subjects as well. The main draw of the model and the IDS is that it can be used to demonstrate the construction techniques of dougong more effectively than previous literature on these types of components. The first reason for this is that the three-dimensional models allow students to piece together the final appearance and details of most dougong, allowing them to picture the overall outcome of the process more clearly. The second reason is that the animations and sequences provided by the IDS can help students follow the process of the dougong assembly more easily than previous literature sources, in that they actively showcase the required pieces being put together. Component-based structures in general can benefit from this type of strategy, because this part-by-part assembly process can demonstrate how the model is assembled without having to rely on a more tedious physical model.

As for the efficacy of the methods presented, a number of criteria can be provided as judgment of the overall educational value. Among the conceptual criteria are the authenticity of the assembly techniques, the clarity of the presentation for both the IDS and the digital models, and the replicability of the components and assemblies in physical form. The technical criteria include animation and model quality, processing speed and power, texture realism, and modular flexibility (i.e. any combination of components can be recreated in theory). Demonstration of the IDS among student audiences ${ }^{10}$ suggested that the models, animations, and simulation performed admirably in both groups of criteria, and the tools and concepts used to create it can be expected to aid in the understanding of other modular structure types as well, such as the Chinese temple as a whole.

\section{Summary and Conclusions}

The complexity of Chinese temples is legendary. The traditional architecture and engineering drawings would now need to be enhanced so students can better comprehend the construction sequence of these temples. Several graduate students are currently working for their theses to create multimedia system that includes 3D animations and step-by-step construction sequences. The most intricate models are the dougong bracket system commonly constructed to support the eaves of the temple roofs. This paper introduces the multimedia system of these dougong 
systems, i.e., the Intelligent Dougong System (IDS), emphasizing on those constructed in the Song Dynasty. The IDS involves the concept and the architectural style behind these dougong components. The IDS covers Song-style dougong based on material recorded in the Yingzao Fashi, and uses the knowledge base for this particular era and component type to display the assembly methods and component configurations, in both graphical and textual form. The various subjects discussed in this paper can be integrated into lessons which, when combined with relevant engineering topics, will allow students to gain a complete picture of the construction of temples in general, as well as envision specific tasks and types of temples. The use of a knowledge base and media organization is also flexible enough to allow for a broadening of the scope of the project.

\section{Acknowledgement}

The authors of this paper gratefully acknowledge the reviewers whose comments have greatly improved the subject matter.

\section{References}

[1] Guo, Qinghua. 1998. "Yingzao Fashi, Twelfth-Century Chinese Building Manual." Architectural History: Journal of the Society of Architectural Historians of Great Britain, vol. 41, pp. 1-13.

[2] Hao, Shilun, Adrian H. Tan, Fabian H. Tan, and Frank M. Croft Jr. 2014. "Simulating the Construction of China's Song-Style Dougong Using Digital Graphics.” Proceedings of the 16th International Conference on Geometry and Graphics, Innsbruck, Austria.

[3] Lee, Josephine, Imogene Lim and Yuko Matsukawa. 2002. Recollecting Early Asian America: Essays in Cultural History. Temple University Press, p. 47.

[4] Li, Jie. 2006. Yingzao Fashi. Beijing: People's Publishing House.

[5] Li, Jiyuan. 2015. An Intelligent Wudian System: A Graphical Simulation for Chinese Temples of Qing Dynasty; Master's Thesis as a partial fulfillment for a Master's Degree in the Construction Program of Department of Civil, Environmental and Geodetic Engineering at The Ohio State University, Columbus, Ohio. The USA.

[6] Liang, Sicheng. 2006. Examples of Gongcheng Zuofa. Beijing: Tsinghua University Press.

[7] Pan, Dehua. 2004. Dougong. Nanjing: Southeast University Press.

[8] Ruitenbeek, Klaas. 1996. Carpentry and Building in Late Imperial China: A Study of the Fifteenth-Century Carpenter's Manual Lu Ban Jing. BRILL, p. 27. 
[9] Shi, Sijun. 2003. Gujianzhu Yingzao Jishu Xibu Tujie (Detailed Graphical Illustrations of the Construction Technology of Ancient Buildings). Shenyang, Liaoning Province, China. Liaoning Science and Technology Publishing House, pp. 77 (in Chinese).

[10]Tan, Adrian H. and Fabian H. Tan. 2015. "A Course in History of Ancient Engineering." Proceedings of the $122^{\text {nd }}$ ASEE Annual Conference and Exposition. 